\title{
К ВОПРОСУ О СООТНОШЕНИИ ПОНЯТИЙ «ДИФФЕРЕНЦИАЦИЯ ПРАВА» И «СПЕЦИАЛИЗАЦИЯ ЗАКОНОДАТЕЛЬСТВА»
}

\begin{abstract}
Аннотация: В статье обращается внимание на проблему диалектической связи процесса дифференииации в системе права с правотворческой деятельностью в виде специализации законодательства. Подчеркивается необходимость четкого разграничения категорий «дифференциация права» и «специализаџия законодательства», а также предлагаются их авторские определения. При этом актуальным и теоретически значимым следует признать установление соотношения понятия «дифференциация права» со смежной категорией «спеииализация законодательства», а также выделение и анализ основных технико-юридических средств и правил проведения спечиализации законодательства. При подготовке статьи применялись такие общенаучные методы, как диалектический и системный методы, анализ, синтез, индукиия, дедукиия, а также частно-научные, в том числе сравнительно-правовой метод. Автор приходит к выводам, что дифференциация в праве вызывает соответствующую специализацию в законодательстве, предопределяет структуру нормативных актов. Если дифференциация права имеет объективный характер и предопределяется потребностью регулирования многообразных общественных отношений, то специализация законодательства имеет производный от нее характер и сопряжена уже с деятельностью по технико-юридическому оформлению содержательных результатов дифференииации. Abstract: The author points out the problem of dialectical link between the process of differentiation within the legal system and lawmaking in the form of specialization of legislation. He underlines the need to clearly demarcate the categories of "law differentiation" and "legislative specialization", and offers their original definitions. During this research, the following general scientific methods were used: analysis, synthesis, induction, deduction, dialectical, systemic, private scientific and legal comparative. The author comes to a conclusion that law differentiation causes corresponding specialization in legislation, and predetermines the structure of normative acts. If the differentiation of law carries an objective character and is predefined by the need to regulate the multifaceted social relations, then specialization of legislation has a character derivative from it and relates to the work on the technical legal formalization of informative results of differentiation. Ключевые слова: Дифференциация права, специализация законодательства, система права, система законодательства, юридическая техника, кодификационные акты, механизм правового регулирования, деление норм права, правовая регламентация, специальные нормы.

Keywords: Law differentiation, legislative specialization, legal system, legislative system, legal methodology, codification acts, legislative regulation mechanism, division of legal norms, legislative regulation, specialized norms.
\end{abstract}

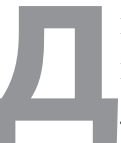

инамика общественной жизни, рост числа нормативно-правовых актов вызывают усложнение системы права и, как следствие, необходимость дифференциации нормативно-правовой материи по различным направлениям, сферам и уровням правового регулирования.

Поскольку право есть продукт, результат особого вида человеческой деятельности, представляется необходимым исследовать вопрос об опосредованности процессов дифференциации в системе права в форме специализации законодательства. В рамках данной статьи речь пойдет о технической стороне выражения и оформления процесса дифференциации правовых обра- зований в ходе правотворческой деятельности. При этом актуальным и теоретически значимым следует признать установление соотношения понятия «дифференциация права» со смежной категорией «специализация законодательства», а также выделение и анализ основных технико-юридических средств и правил проведения специализации законодательства. Отдельного внимания заслуживает проблема влияния дифференциации в праве на технологию структурирования кодификационных актов и системы законодательства в целом.

Термин «дифференциация» происходит от французского слова «differentiation» и от латинского «differentia»- разность, различие. 
Дифференциация права - это одна из основополагающих, наряду с интеграцией, тенденций в развитии и функционировании системы права, имеющая многоуровневый характер, выражающаяся в непрерывном процессе переменной интенсивности дробления, выделения новых структурных образований в праве, в увеличении числа его элементов, в расширении круга выполняемых ими функций, а также в вызревании качественных различий элементов (и подсистем), посредством чего обеспечивается должный уровень разнообразия в механизме правового регулирования и адаптация его к внешней среде.

Следует согласиться с И.Н. Сенякиным в том, что тенденция дифференциации действует практически во всех отраслях законодательства и будет в дальнейшем постоянно развиваться ${ }^{1}$. Именно данный процесс выделяет в структуре права все новые элементы в качестве ответной реакции на постоянное увеличение разнообразия в системе регулируемых общественных отношений. Дифференциация выступает необходимым спутником правового прогресса, обеспечивает баланс между общностью и детализированностью механизма юридического воздействия.

Потребность в дифференциации правовой материи, в первую очередь, обусловлена самими общественными отношениями, степенью их разнообразия и сложности. В связи с этим дифференциация в праве может быть однофазовой и многофазовой ${ }^{2}$. На многоступенчатый процесс дифференциации в системе права изначально обратили свое внимание представители отраслевых юридических наук ${ }^{3}$. В общей теории права указанная проблема требует дальнейшего развития.

Итогом однофазовой (односложной) дифференциации выступает деление норм права на отдельные виды, производные от какого-либо одного или нескольких общих предписаний (например, от норм общей части, принципа права, правовой дефиниции и т.д.). Что важ-

\footnotetext{
${ }^{1}$ См.: Сенякин И.Н. Специализация и унификация Российского законодательства / Под ред. М.И. Байтина. Саратов: Изд-во Саратовского УН-та, 1993. С. 58.

${ }^{2}$ См.: Там же. С. 59; Поленина С.В. Теоретические проблемы системы советского законодательства. М., 1979. С. 167-176.

${ }^{3}$ См., например: Клейн Н.И. Организация договорно-хозяйственных связей. М., 1976. С. 173-175; Петров И.Н. Тенденции развития законодательства о народном хозяйстве // Конституция СССР и Законодательство развитого социализма. М., 1984. С. 189; Свидлов Н.М. Специальные нормы в уголовном праве: Автореф. дисс. .... канд. юрид. наук. М., 1979. С. 6, 11; Юков М.К. Специализация норм гражданского процессуального права // Проблемы совершенствования советского законодательства. Труды. - М.: Изд-во ВНИИСЗ, 1986, Вып. 34. - С. 117 и др.
}

но, дальнейшее деление уже видовых специальных норм не требуется в виду специфики регулируемых общественных отношений. Правовая регламентация определенного вида социальных отношений исчерпывается в данном случае рядом общих предписаний и специальными нормами одного уровня.

В ходе многофазовой (сложной) дифференциации можно выделить несколько фаз (этапов) ее осуществления. Помимо первого этапа, на котором дифференцируются общие предписания на специальные, имеются последующие ступени деления. Так, уже специальные нормы подвергаются дифференциации второго, третьего порядка и т.д. Как уже отмечалось в литературе, в силу возрастания многообразия и сложности социально-экономических и политических процессов в юридической практике доминирует многофазовая дифференциация ${ }^{4}$.

В качестве примера поэтапной реализации процесса дифференциации в современном российском праве выступает механизм правового регулирования труда работников отдельных категорий. В трудовом праве Российской Федерации имеет место модель правового регулирования, обладающая различными уровнями (различной степенью) единства и разными уровнями правовой дифференциации 5

Дифференциация нормативных предписаний в трудовом праве характеризуется высокой степенью интенсивности своего осуществления, что обусловлено ускоряющимся процессом развития экономических отношений в целом и трудовых в частности. Специалистами в области трудового права уже давно подмечено, что возможности по дифференциации правового регулирования труда, по сути, безграничны $^{6}$. Постоянное усложнение трудовых отношений с неизбежностью вызывает появление новых критериев (факторов) дифференциации норм данной отрасли права. Особенно интересен тот факт, что в настоящий момент законодатель зачастую не успевает за реальными процессами дифференциации в сфере трудовых отношений. В свою очередь, указанное обстоятельство

\footnotetext{
${ }^{4}$ См.: Сеняин И.Н. Указ. соч. С. 59.

${ }^{5}$ См.: Абалдуев B.A. Оплата труда работников бюджетной сферы: единство и дифференциация правового регулирования // Проблемы дифференциации в правовом регулировании отношений в сфере труда и социального обеспечения: Материалы V межд. науч.-практич. конф. / Под ред. К.Н. Гусова. М.: Проспект, 2009. C. 249; Халдеева Н.B. О некоторых вопросах защиты трудовых прав работников Крайнего Севера в их единстве и дифференциации // Социальное и пенсионное право. 2012. N 1. С. 30 - 33.

${ }^{6}$ См.: Рабинович-Захарин С.Л. Единство и дифференциация советского трудового права: Дис. ... канд. юрид. наук. М., 1947. С. 5.
} 
DOI: $10.7256 / 1811-9018.2014 .11 .13363$

При цитировании этой статьи сноска на dоі обязательна

\section{Право и политика $11(179) \cdot 2014$}

свидетельствует о необходимости «отстающей» специализации нормативно-правового материала, возможности которой далеко не исчерпаны в трудовом праве

Термин «специализация» в ряде гуманитарных наук используется при характеристике того или иного рода социальной деятельности, отражая специфику «разделения труда» в экономике, политике, образовании и т.д В биологии понятие «специализация» призвано отражать определенные моменты в приспособлении живых организмов к разнообразным условиям внешней среды9.

Применительно к правовой жизни рассматриваемый термин логично использовать в отношении «разделения труда» в рамках того или иного вида юридической деятельности (практики). Так, одним из специфических видов выступает правотворческая деятельность, в рамках которой и можно вести речь о специализации законодательства, а также о ее противоположной тенденции - унификации нормативно-правовых актов. В связи с этим юридическая наука вполне обоснованно оперирует категорией «специализация» в ходе описания деятельности по развитию и совершенствованию законодательства в России.

Термин же «дифференциация права», безусловно, самым тесным образом связан с правотворческой деятельностью по специализации законодательства, но имеет иной ракурс отражения юридической материи. Термины «интеграция» и «дифференциация» в соответствии с системным подходом следует использовать при описании внутренних процессов объединения и выделения элементов в структуре права, что находит свое внешнее оформление в ходе правотворческой деятельности по унификации и специализации законо-

\footnotetext{
${ }^{7}$ См.: Орловский Ю.П. Единство и дифференциация трудового законодательства // Материалы международной научно-практической конференции «Право человека на жизнь и гарантии его реализации в сфере труда и социального обеспечения». М., 2008. C. $29-30$.

${ }^{8}$ Специализация - это: 1) сосредоточение деятельности на относительно узких направлениях, отдельных технологических операциях или видах выпускаемой продукции; 2) приобретение специальных знаний и навыков в определенной области; 3) разделение труда по его отдельным видам, формам. - Борисов А.Б. Большой экономический словарь. М.: Книжный мир, 2003.

${ }^{9}$ Специализация (франц. specialisation, от лат. specialis - особый, особенный, species - род, вид, разновидность) есть направление эволюционного процесса, приводящее к выработке у организмов максимальных приспособлений для жизни в менее разнообразных, по сравнению с предками, условиях окружающей среды и снижению конкуренции с другими видами. - См. подробнее: Шмальгаузен И. И., Пути и закономерности эволюционного процесса, М. - Л., 1939; его же, Проблемы дарвинизма, 2 изд., Л., 1969; Тимофеев-Ресовский Н. В., Воронщов Н. Н., Яблоков А. В., Краткий очерк теории эволюции, М., 1969.
}

дательства. Диалектическая связь указанных явлений и процессов не отменяет, имеющихся у них различий и не порождает их полного тождества.

Однако в литературе порой некорректно используется термин «дифференциация» в отношении процесса правотворчества и средств законодательной техники, где правильнее употреблять термин «специализация». Так, К.В. Каргин, обращаясь к вопросам терминологии законодательства, в качестве парной абстракции к понятию «унификация» неточно определяет категорию «дифференциация» ${ }^{10}$. Как уже было отмечено, в общенаучном плане понятие «специализация» преимущественно применяется для отражения процессов «разделения труда» в той или иной сфере человеческой деятельности, поэтому в данном случае необходимо использовать термин «специализация терминологии нормативных правовых актов», ибо речь идет об инструменте законодательной техники и его использовании в ходе правотворческой деятельности.

Иногда отдельные авторы не разграничивая четко «дифференциацию в праве», «интеграцию права» и «специализацию законодательства», делают попытку привлечения внимания к проблеме их взаимосвязи, но смешение понятий делает их выводы не вполне ясными и противоречивыми. Так в литературе отмечается, что «дифференциация норм права на отрасли влечет за собой, как правило, интеграцию законодательства, а межотраслевая интеграция норм права зачастую - дифференциацию законодательства, возрастание множественности актов» ${ }^{11}$. Вопрос о первичности дифференциации в системе права над процессом специализации в законодательстве остается у исследователя открытым с долей противоречия в суждениях. Сложность обозначенных явлений требует от научной теории большего внимания к ним и большей точности в их разграничении.

В самом общем виде специиализащию законодательства можно определить как особый вид целенаправленной, интеллектуально-волевой деятельности субъектов правотворчества, выражающийся в виде

\footnotetext{
${ }^{10}$ См.: Каргин К.В. Унификация и дифференциация терминов «доказывание» и «аргументация» в процессуальных отраслях системы российского права // Система права в Российской Федерации: проблемы теории и практики: Сб. научн. ст. Материалы V ежегодной международной научной конференции, 19-22 апреля 2010 г. / Отв. Ред. В.М. Сырых, С.А. Рубаник. М., 2011. С. 343-351.

${ }^{11}$ Курохтин Ю.А. Проблемы соотношения системы права и системы законодательства // Система права в Российской Федерации: проблемы теории и практики: Сб. научн. ст. Материалы V ежегодной международной научной конференции, 19-22 апреля 2010 г. / Отв. Ред. В.М. Сырых, С.А. Рубаник. М., 2011. С. 343-351.
} 
предметно-отраслевого и функционального деления системы законодательства на отрасли, общие и специальные нормативные акты, подразделения структуры кодификационных актов на общие и особенные части посредством применением специальных правил и средств юридической техники. В числе последних представляется возможным выделение конкретизации законодательства как особого технического способа, классификации, специализации юридической терминологии, отсылок, оговорок, примечаний.

Надлежащий уровень специализации законодательства обеспечивает наиболее правильное толкование и применение норм права, облегчает процесс индивидуализации нормативных предписаний применительно к разрешению конкретного случая на практике. В механизме правового регулирования можно представить взаимосвязь процесса дифференциации права и специализации законодательства в виде следующей схематичной цепи: «дифференциация общественных отношений - дифференциация права - специализация законодательства - индивидуализация правового регулирования общественных отношений».

На практике нередки случаи правотворческих ошибок в ходе проведения работ по специализации законодательства. Так, например, законодатель порой проводит преждевременную или неоправданную специализацию нормативно-правовых актов, устанавливает избыточное число специальных и конкретизирующих нормативных предписаний, что приводит к коллизиям норм, правовой инфляции.

Заметим, что дифференциация в праве и специализация в законодательстве, безусловно, выступают взаимосвязанными явлениями, но все же нетождественными. При этом еще раз подчеркнем, что именно специализация законодательства является формой дифференциации в праве, а - не наоборот (как законодательство является одной из форм права, a - не его содержанием). Причины же, вызывающие рассматриваемые феномены, одни и те же.

С усилением начал дифференциации в праве обозначается определенная тенденция и в специализации законодательства. В связи с этим в нормативных актах регулятивные и охранительные нормы подчас все больше отдаляются друг от друга, включая создание специализированных актов, содержащих преимущественно охранительные предписания (например, УК РФ).

Динамика дифференциации структур в праве может опережать процесс специализации законодательства, и наоборот, - законодатель может забегать вперед или неоправданно осуществлять обособле- ние в нормативных актах правовых предписаний, не имеющих тесных связей между собой и не обладающих самостоятельностью в регулировании общественных отношений.

Вызывает интерес мысль С.С. Алексеева о том, что в системе права имеют место становящиеся образования, т.е. находящиеся в стадии зарождения, формирования. К их числу автор относил правовые комплексы, которые еще не обрели должной самостоятельности, черт элемента системы. Он называл их ассоциациями нормативных предписаний, объединениями правовых институтов ${ }^{12}$. Рассматриваемая проблема акцентирует наше внимание том обстоятельстве, что процесс дифференциации в праве весьма динамичен, имеет непрерывный характер и в качестве своего результата может иметь становящиеся образования, неустойчивые структуры (они могут оформиться в самостоятельные элементы права, либо могут распасться). В последнее время законодатель подобные неустойчивые правовые образования спешит оформлять в виде отдельных отраслей законодательства, что порой приводит к его излишней и преждевременной специализации.

Подчеркнем и то обстоятельство, что дифференциация в системе права не приводит к изоляции норм, институтов и отраслей друг от друга, функционирование каждого из обозначенных элементов оказывается неизбежно связанным с действием ряда других. Лишь в своей совокупности, будучи включенными в систему, отдельные нормы, институты и отрасли права способны при соответствующих усилиях со стороны правоприменителя оказывать надлежащее воздействие на общественные отношения. Таким образом, процесс дифференциации правовых образований обусловливает необходимость при анализе отдельной общности правовых норм учитывать ее связи со многими другими нормами, институтами и отраслями. Вместе с тем, на наш взгляд, необходимо нахождение в теории всей суммы общих закономерностей, объясняющих установление состояния сбалансированности дифференциации и интеграции как двух важнейших тенденций в развитии российского права.

На диалектическую взаимосвязь дифференциации права и специализации законодательства справедливо обращает внимание И.Н. Сенякин на примере технологии структурирования кодификационных актов. Так, дифференциация правовых норм по функциям влечет за собой их обособление в нормативно-правовых актах,

\footnotetext{
${ }^{12}$ См.: Алексеев С.С. Структура советского права. С. 43.
} 
DOI: $10.7256 / 1811-9018.2014 .11 .13363$

При цитировании этой статьи сноска на dоі обязательна

\section{Право и политика $11(179) \cdot 2014$}

в первую очередь, в кодексах ${ }^{13}$. В данном случае имеет место распределение общих и специальных норм в соответствующих частях кодификационных актов. На наш взгляд, автор, в целом верно описывая сущность процессов специализации законодательства, все же не проводит необходимой грани между процессами дифференциации права и специализации законодательства. Дифференциация правовых норм по функциям действительно вызывает соответствующую специализацию в законодательстве, в кодификационных актах, предопределяет их структуру. Но все же эти процессы не тождественны. Если дифференциация права имеет объективный характер и предопределяется потребностью регулирования многообразных общественных отношений, то специализация законодательства имеет производный от нее характер и сопряжена уже с деятельностью по технико-юридическому оформлению содержательных результатов дифференциации. Дифференциация права, не совпадая по ряду параметров со специализацией законодательства, представляется нам первичной по отношению к ней.

Процессы дифференциации права, безусловно, должны учитываться законодателем в ходе распределения нормативного материала в кодификационных актах, а также при проведении специализации законодательства в целом. На первичность дифференциации права по отношению к специализации законодательства справедливо обратил внимание С.С. Алексеев: «Хотя распределение нормативного материала в кодифицированных нормативных актах по разделам, главам, статьям в ряде случаев определяется чисто классификационными, социально-политическими и некоторыми другими задачами, но и здесь в определенной степени проступает структура права, его реальное подразделение на институты, нормативные предписания и их объединения... Законодатель не волен (без ущерба для эффективности права) по своему свободному усмотрению «кроить и перекраивать» нормативные юридические акты, произвольно изменять их строение и иерархию» ${ }^{14}$.

По сути, о возможном несовпадении процессов специализации законодательства и дифференциации в праве говорит и И.Н. Сенякин: «... если процесс специализации не затрагивает сути его внутренней стороны в любой форме (дифференциации, конкретизации, детализации), то такой акт зачастую малоэффективен или

\footnotetext{
${ }^{13}$ См.: Сенякин И.Н. Указ. соч. С. 27.

${ }^{14}$ Алексеев С.С. Структура советского права. М., 1975. С. 61.
}

совсем не применяется на практике» ${ }^{15}$. Такой вариант на практике выражается в проведении правотворческим органом работ по специализации нормативно-правовых актов без объективной необходимости, вне потребности в дифференциации правовых норм состоянием общественных отношений, что является негативным проявлением правовой жизни.

Правотворческие органы в идеале должны так проводить специализацию законодательства, чтобы она в максимальной степени соответствовала процессам внутренней дифференциации структурных образований права. Следует упомянуть о том, что если специализация законодательства в целом показывает нам лишь общие контуры дифференциации в праве, то состав, структура и подразделение статей кодификационных актов позволяют увидеть конкретные примеры дифференциации системы права на уровне отдельных норм, институтов и их объединений.

При этом процесс специализации законодательства оказывает обратное воздействие на дифференциацию правовой материи. Порой недостатки в специализации законодательства с определенными трудностями вынуждена преодолевать судебная практика, беря на себя по сути функции правотворческого органа. В этих целях используются инструменты аналогии закона и права, закрепление в судебных актах толкования фактически недостающих специальных норм в законе.

Специализация должна проводиться с учетом строения права не только в системе законодательства в целом, но и в отношении внутренней структуры отдельных нормативных актов. Структуру кодификационного акта необходимо тщательно продумывать и согласовывать ее с реальной структурой той или иной отрасли права, межотраслевого института. Деление нормативно-правового акта на части, разделы, главы, статьи в своей основе должно учитывать объективно существующие закономерности дифференциации, дробления самого права и его частей. Например, желательно, чтобы глава кодификационного акта содержала нормы одного института права, выделение которого было бы тем самым оформлено и посредством специализации в законе.

С учетом изложенного, разграничение рассматриваемых процессов позволяет точнее отразить в теории основополагающие закономерности функционирования и развития системы права и системы законодательства. На практике же дифференциация структурных образований права, надлежащим образом закрепленная в за-

\footnotetext{
${ }^{15}$ Сенякин И.Н. Указ. соч. С. 41.
} 
DOI: $10.7256 / 1811-9018.2014 .11 .13363$

При цитировании этой статьи сноска на dоі обязательна

Правоведение

конодательстве посредством специализации нормативных актов и их структурного деления, в значительной степени повышает эффективность механизма правового регулирования в целом. Учет реально существующих закономерностей дифференциации и интеграции права является одним из важнейших требований юридической техники проведения работ по специализации и унификации законодательства.

\section{Библиография:}

1. Алексеев С.С. Структура советского права. М.: Юрид. лит., 1975. 258 с.

2. Асадов А.М., Драхенберг Т.В. К вопросу о телеологическом критерии дифференциации системы российского права // Проблемы права. 2012. № 2. С. 176-181.

3. Поленина С.В. Теоретические проблемы системы советского законодательства. М.: Изд-во «Наука», 1979.209 с.

4. Попондопуло В.Ф. Проблемы единства и дифференциации российского права и законодательства // Российский юридический журнал. № 1 (76). Екатеринбург: Изд-во УрГЮА, 2011. С. 26-37.

5. Реутов В.П. Развитие взглядов на отраслевую дифференциацию права // Проблемы развития российского законодательства. Сборник статей. Пермь: Изд-во Перм. ун-та, 2002. С. 4-18.

6. Сенякин И.Н. Специализация и унификация российского законодательства. Проблемы теории и практики / Под ред. М.И. Байтина. Саратов: Изд-во Сарат. ун-та, 1993. 244 с.

7. Система права в Российской Федерации: проблемы теории и практики: Сборник научных статей. Материалы V ежегодной международной научной конференции, 19-22 апреля 2010 г. / Отв. ред. В.М. Сырых, С.А. Рубаник. - М.: РАП, 2011.

8. Сырых В.М. Логические основания общей теории права в 3-х томах. Т.3. Современное правопонимание. М.: РАП, 2007. $512 \mathrm{c.}$

\section{References (transliterated):}

1. Alekseev S.S. Struktura sovetskogo prava. M.: Yurid. lit., 1975. $258 \mathrm{s.}$

2. Asadov A.M., Drakhenberg T.V. K voprosu o teleologicheskom kriterii differentsiatsii sistemy rossiiskogo prava // Problemy prava. 2012. № 2. S. 176-181.

3. Polenina S.V. Teoreticheskie problemy sistemy sovetskogo zakonodatel'stva. M.: Izd-vo «Nauka», 1979. 209 s.

4. Popondopulo V.F. Problemy edinstva i differentsiatsii rossiiskogo prava i zakonodatel'stva // Rossiiskii yuridicheskii zhurnal. № 1 (76). Ekaterinburg: Izd-vo UrGYuA, 2011. S. 26-37.

5. Reutov V.P. Razvitie vzglyadov na otraslevuyu differentsiatsiyu prava // Problemy razvitiya rossiiskogo zakonodatel'stva. Sbornik statei. Perm': Izd-vo Perm. un-ta, 2002. S. 4-18.

6. Senyakin I.N. Spetsializatsiya i unifikatsiya rossiiskogo zakonodatel'stva. Problemy teorii i praktiki / Pod red. M.I. Baitina. Saratov: Izd-vo Sarat. un-ta, 1993. 244 s.

7. Syrykh V.M. Logicheskie osnovaniya obshchei teorii prava v 3-kh tomakh. T.3. Sovremennoe pravoponimanie. M.: RAP, 2007. 512 s. 